\title{
Chapter 5 \\ Family Trajectories and Life Satisfaction: The Swiss Case
}

\author{
Boris Wernli and Sara Zella
}

\section{Introduction}

It would not be surprising to say that life has ups and downs and that its instability is caused by the events that individuals experience over time. The number of articles on happiness and well-being that appear in mainstream journals have proven a strong association between well-being and health, work career, social contacts and family episodes (Dolan et al. 2008). In this chapter, we focus on the relationship between family and happiness, which is motivated by the several changes that a family may experience and by the role that different family events may play on well-being (Vignoli et al. 2014). Expanding upon previous research on this topic, we consider five events that indicate the construction or, oppositely, the dissolution of family. The first situation is distinguished by the formation of the union, the transition from cohabitation to marriage and the birth of children. Dissolution is defined by the departure of a child from the parents' house and episodes of the divorce/ separation.

Existing studies on family events and well-being support the theoretical predictions of the positive association between being in a relationship and life satisfaction (e.g. Kohler et al. 2005) and the negative impact of divorce on happiness (e.g. Kalmijn 2009). More scarce and mixed are the results of the presence of children on happiness (Aassve et al. 2012; Billari 2009; Kohler et al. 2005).

\footnotetext{
B. Wernli $(\bowtie)$

Swiss Centre of Expertise in the Social Science (FORS), University of Lausanne,

Lausanne, Switzerland

e-mail: boris.wernli@unil.ch
}

\section{S. Zella}

Swiss Centre of Expertise in the Social Science (FORS) and Oxford Institute of Population Ageing, University of Oxford, Oxford, UK

e-mail: sara.zella@ageing.ox.ac.uk 
Following the mainstream research in recent years, we used a longitudinal perspective to reach a double aim. First, we did so to understand how the mentioned events are associated with changes in subjective well-being. Second, we aimed to capture the duration of this effect. Specifically, we asked whether the mentioned events have only a temporary effect on well-being or whether this impact lasts for a longer time (Anusic et al. 2013; Lucas et al. 2003; Myrskylä and Margolis 2014).

We focussed on the Swiss context and used fourteen years of the Swiss Household Panel (SHP).

\section{Family Events and Well-Being}

Across several decades, the literature has highlighted the positive effects of being part of a couple (cohabitant and married) on well-being (e.g. Kohler et al. 2005). The reasons are mainly associated with social, economic and emotional support mechanisms. Indeed, having a partner seems to help individuals cope with the difficulties of life, feel less lonely and feel less helpless (Blanchflower and Oswald 2004), and it encourages sharing resources and financial responsibility. However, a jarring challenge to the consensus of the positive effects of the creation of a couple on well-being was proposed in recent years. A rising question asks whether the level of happiness (derived from having a partner) dissipates over time, rather than remaining stable and, more generally, whether an individual can adapt to a new (expected or unforeseen) family situation.

In the literature on happiness and family, one of the first studies that answered this question was proposed by Lucas et al. (2003). They concluded that the creation of a couple only increases the life satisfaction of the partners temporarily, and typically, they revert two years after marriage to the same "baseline" level of life satisfaction that prevailed two years prior. Similarly, Lucas and Clark (2006) and Stutzer and Frey (2006) identified a sort of "honeymoon effect" in Germany, and Angeles (2010) found an analogous effects in the U.K. Angeles (2010) also underlined important differences between genders: women have a larger positive effect than men, they enjoy an anticipation effect of one year and their level of satisfaction remains statistically significant until three years after marriage (whilst for men it lasts only one year). Anusic et al. (2013) showed that Swiss individuals are not happier after marriage, but they have a higher well-being level than they would if they had remained single.

Following the previous findings, we hypothesize that unions are positively associated with life satisfaction, both for Swiss women and for Swiss men; however, we expect to find a "honeymoon effect". Therefore, the year before and the years during the union may be characterised by the highest level of life satisfaction, which may tend to decrease a few years afterwards, but it presumably remains higher than before this event (Zimmermann and Easterlin 2006).

The adaptation approach has also been used in the studies on divorce, separation and widowhood. There has been the general consensus that these events (divorce in 
particular) have a negative effect on one's well-being (e.g. Williams and Umberson 2004; Kalmijn and Monden 2009). Nevertheless, results were conflicting when using the longitudinal approach. For example, Amato and Booth (1991) found that people can adapt to situations of divorce, whilst Johnson and Wu (2002), using the same data, contradicted these results and concluded that divorce was associated with permanent changes in levels of distress. Lucas (2005) showed that an individual's satisfaction drops as one approaches divorce, then it gradually rebounds over time, but the return to baseline is not complete. Finally, Clark et al. (2008) found that habituation to divorce is rapid and complete, and they proved that both men and women who are divorced for more than four years are currently significantly more satisfied with their lives.

We expect similar behaviour in dealing with the divorce of Swiss couples: large losses in happiness and a strong anticipation effect. We hypothesize that the initial fall in happiness will disappear after few years, but that individuals will not reach their pre-divorce level of happiness (Lucas 2005). In addition, differences between genders may exist. Men probably suffer more than women at the time of the break (Angeles 2010), but they might recover faster than females.

Whilst the creation of a couple and its disintegration have straightforward effects on life satisfaction, more contradicted are the results on the transition to parenthood (Aassve et al. 2012; Billari 2009; Kohler et al. 2005). Psychological studies suggest negative consequences are associated with childbearing, as parents experience stress that is related to increased financial responsibilities (Zimmermann and Easterlin 2006) and reduce their leisure time, and the quality of the couple's relationship also tends to decrease (Lavee et al. 1996). In the opposite direction is the fertility theory, which suggests a positive link between life satisfaction and parenthood. Billari (2009) suggested that fertility is positively correlated with happiness, but is mediated by the policy environment. In another study, Angeles (2010) found that the birth of a child brings important happiness to women, with an anticipation effect of one year and a similar large effect at the time of birth. For men, there is an anticipation effect (though smaller than that of women), but there is an absence of such an effect at the time of birth.

Since trajectories capture not only the effect of birth but the broader process of childbearing (Myrskylä and Margolis 2014), we expect that happiness increases before a birth. In particular, Swiss women may gain more in happiness in expectation and right after a birth than Swiss men, but they may experience steeper drops the following years (Clark et al. 2008). Part of the stronger dip may be due to a larger anticipation effect, but it may also be due to the fact that women are more socially isolated after childbirth, as they have often taken leave from the labour force and act as the primary caregiver, particularly when the child is young (Della Giusta et al. 2011; Simon 1992).

Last, we consider the departure of children from their parents' home. Despite strikingly less attention being devoted to this event in the literature (Bouchard 2014), it is of great concern to researchers for two main reasons. First, because an empty nest engenders complex emotions for parents, both positive and negative (Beaupré et al. 2006; Dare 2011). Second, understanding the conditions under 
which couples can experience a more positive transition constitutes one of the first steps in promoting well-being among couples. Two perspectives have been developed in recent years: the role loss perspective and the role strain (relief) perspective. The first perspective predicts a decrease of parents' well-being as a consequence of a child's departure. In sharp contrast to the hypothesis of a loss, the role of strain relief perspective suggests that the empty-nest stage leads to improved parental well-being, since children at home increase exposure to stressors, such as daily demands and work-family conflicts (Erickson et al. 2010; Umberson et al. 2010; White and Edwards 1990). Notwithstanding, research has been slightly incoherent regarding the impact of the departure of a child from home, and the majority of studies published in recent decades have painted a more optimistic picture. They underline that only the absence of alternative roles in which to continue building an identity (after children leave home) explains the negative effects of children's departure on parents' well-being (e.g. Raup and Myers 1989). Looking at longitudinal studies in North America and Europe, we hypothesize that in Switzerland, the positive effect of the empty nest on parental well-being also appears to be stronger immediately after the children take their leave (White and Edwards 1990); it then decreases and tends to disappear after few years (Harkins 1978).

\section{Data}

The different subsamples of SHP (Tillmann et al. 2016) participants who completed the individual questionnaire are defined differently depending on the transition under study. For each transition, individuals were followed from wave 3 (2001) until wave 16 (2014). The first two waves are not included in our study due to the late inclusion of some indicators in the questionnaire. The composition of the different samples is explained in the follow section.

Formation of the Union At the beginning of our observation window, only single individuals were included. They could live with a partner (or not) in subsequent waves. Cases with children or with other persons living together were not considered to decontaminate this transition from other potential influences. Our sample comprises 3241 persons (1903 women and 1338 men) who fulfil the abovementioned conditions and who have validly completed the individual questionnaire on all the considered variables (complete cases). In total, 17,188 valid ${ }^{1}$ observations were considered during this analysis.

From Cohabitation to Marriage We ran analyses for two different samples. The first sample includes only partners living in a two-person household, excluding individuals living with children or other persons (parents, etc.). At the start of our observation window, all these individuals were not married (they can be single, divorced

\footnotetext{
${ }^{1}$ With non-missing values for every variable included in the model.
} 
or widowed ${ }^{2}$ ). In total, 2035 individuals (1064 women and 971 men) fulfilled these conditions, corresponding with 7197 complete cases. In the second sample, we did not impose restrictions on the household size. Therefore, children or other persons were possibly in the household before, during and after this transition. As before, selected individuals were living together with a partner at the start of the period under review and could get married (or not) during the subsequent waves. The sample comprised 2700 individuals ( 1421 women and 1279 men), who were followed during 12,507 complete observations.

Birth of Children In total, 15,013 individuals were considered (8034 women and 6979 men), for a total of 94,205 full observations, without an age limit or any restrictions concerning the composition of the households. Even individuals without partners were considered here, although their chances to experience this transition were low.

Dissolution of the Union We considered the persons living with a partner at the beginning of their period under review. The sample consisted of 9742 individuals (5155 women and $4587 \mathrm{men}$ ), all followed during 61,115 complete periods.

Departure of Children The initial sample included individuals living with a partner and one or more children. In addition, the couple remained together even after the departure of the child. In total, 5403 parents ( 2875 women and 2528 men) were followed, corresponding to 36,002 complete episodes.

\section{Variables}

Our dependent variable is life satisfaction, measured at each wave on an 11-point scale ranging from 0 to 10 , with 5 as a neutral position. ${ }^{3}$

The transitions under study are defined as changes from the initial status in the interval of two successive waves. We studied their impact on the mid-term and therefore did not focus only on the observation just after the transition; rather, we it took into consideration two years before and after the event. Therefore, we constructed five dichotomous variables, indicating the two years before $(\mathrm{t}-2, \mathrm{t}-1)$, the year of the transition $(\mathrm{t} 0)$ and the two following two years $(t+1, t+2)$. The reference category is any year (before or after) which is not included in the five-year string surrounding the abovementioned transitions. Transitions occurring when a wave was skipped were not taken into consideration, given the difficulty of timing events precisely and building accurate measurements.

As control variables, we include the wave of the survey to control for the potential effects of the period. The ages of the respondents were introduced as a set of

\footnotetext{
${ }^{2}$ To get potentially married at the subsequent wave.

3 "In general, how satisfied are you with your life if 0 means 'not at all satisfied' and 10 means 'completely satisfied'?"
} 
dichotomous variables, given their potential nonlinear impact: less than 30 years, 30 to 44 years, 45 thru 64 years and 65 years and older, the latter being the reference category. Education was introduced as a continuous scale, ranging from 0 to 10 , representing the standardized levels of education in the Swiss system; its linear effect on our dependent variable was verified beforehand. Working time is expressed as a percentage of full-time work, and net yearly household income (in 10,000 Swiss Fr) was also considered, with missing values imputed (10\% to $15 \%$, depending on the wave) using the Little and Su procedure (Lipps 2010). Two parameters of health were considered. First, satisfaction with health status ${ }^{4}$ was considered as a proxy of health. Second, we used a variable related to health impediments in everyday activities. ${ }^{5}$ Financial satisfaction was taken into account and was evaluated on a scale of $0-10$, using 0 for "not satisfied" and 10 for "very satisfied", as well as satisfaction of the individual's interpersonal relationships. ${ }^{6} \mathrm{We}$ also considered participation in clubs or other groups, ${ }^{7}$ satisfaction with free time ${ }^{8}$ and satisfaction with leisure activities $^{9}$ for each wave to control for these aspects, which are recognized to have an influence on life satisfaction. Finally, we included a dichotomous variable stating whether the interviewee lived with a partner in the model, predicting the impact of the birth of children to consider lone parents in the analysis.

The inclusion of other satisfaction variables as controls can be criticized for theoretical reasons, but similar models were run without these variables with equivalent results.

\section{Analytical Tool}

To evaluate the mid-term impact of the events shaping family trajectories with longitudinal data, we estimated a set of multilevel linear models (MLMs) (Hox 2002; Singer and Willett 2003) using the SPSS software (which is notably similar to the SAS Proc Mixed procedure).

These MLMs were designed for longitudinal data (Hox 2002; Singer and Willett 2003 ) with several observations in a varying number per individual. For these mod-

\footnotetext{
4 "How satisfied are you with your state of health, where 0 means 'not at all satisfied' and 10 is 'completely satisfied'?"

5 "Please tell me to what extent, generally, your health is an impediment in your everyday activities, in your housework and in your work or leisure activities? Note that 0 means 'not at all' and 10 is 'a great deal'."

6 "How satisfied are you with your personal, social and familial relationships, where 0 means 'not at all satisfied' and 10 is 'completely satisfied'?"

7 "Do you take part in clubs or other group activities, including religious groups?"

8 "How satisfied are you with the amount of free time you have, where 0 means 'not at all satisfied' and 10 is 'completely satisfied'?"

9 "How satisfied are you with your leisure time activities, where 0 means 'not at all satisfied' and 10 is 'completely satisfied'?"
} 
els, repeated observations of the same individual constitute a sub-level ${ }^{10}$ of the analysis that takes the form of a composite multilevel model for change (Hox 2002; Singer and Willett 2003). The continuous dependent variables (positive and negative effects) are the linear sum of the structural components (first bracket of Eq. 5.1 below), which have the same effect for all individuals, whereas error terms ${ }^{11}$ are randomly distributed among individuals.

$$
\begin{gathered}
Y_{i j}=\left[\gamma_{00}+\beta_{1} \cdot x_{1 i j}+\beta_{2} \cdot x_{2 i j}+\ldots+\beta_{p} \cdot x_{p i j}\right]+\left[\mu_{0 j}+\varepsilon_{i j}\right] \\
\text { where } i=\text { waveindex and } j=\text { individual index } \\
\quad \text { where } \mu_{0 j} \sim N\left(0, \tau_{00}\right) ; \operatorname{cov}\left(\varepsilon_{i j} \varepsilon_{i^{\prime} j}\right)=\sigma^{2} \rho^{\left|i-i^{\prime}\right|}
\end{gathered}
$$

The residuals (last bracket of Eq. 5.1) are divided into two parts. In addition to the varying error term for each observation ( $(\varepsilon \mathrm{ij})$, which is common to every regression equation, we also considered a second error term $(\mu 0 \mathrm{j})$ that remains constant for all observations of the same individual. This approach allowed us to structure the residuals and correlate them across waves.

The chosen model is a first-order autoregressive structural model of the covariance of the residuals (AR1), which is a common choice for repeated measures. It means that, for a given individual, the residuals are correlated from one observation to the next, but in a variable fashion as a function of their proximity. Significant AR1 diagonal (covariance) and AR1 rho (correlation with the preceding observation) coefficients in our analyses demonstrate the pertinence of this choice.

Our models are estimated separately for each sex and are not weighted for two reasons: first, weights distort the gathered data on the basis of sociodemographic parameters, but nothing ensures that representativeness will be reached concerning the variable of interest, namely life-satisfaction; and second, indicators used for weighting are already controlled in our models.

\section{Results}

\section{The Family Construction}

Table 5.1 presents the first two transitions associated with the construction of the family, namely the formation of the union and the transition from cohabitation to marriage.

\footnotetext{
${ }^{10}$ Our models distinguish only two levels (observations and individuals), given the fact that equations are run separately for women and for men. Intra-household correlations within partners living together are thus avoided.

${ }^{11}$ Error terms have a standard normal distribution (a mean of 0 ), an unknown variance and a structure that can be modeled.
} 


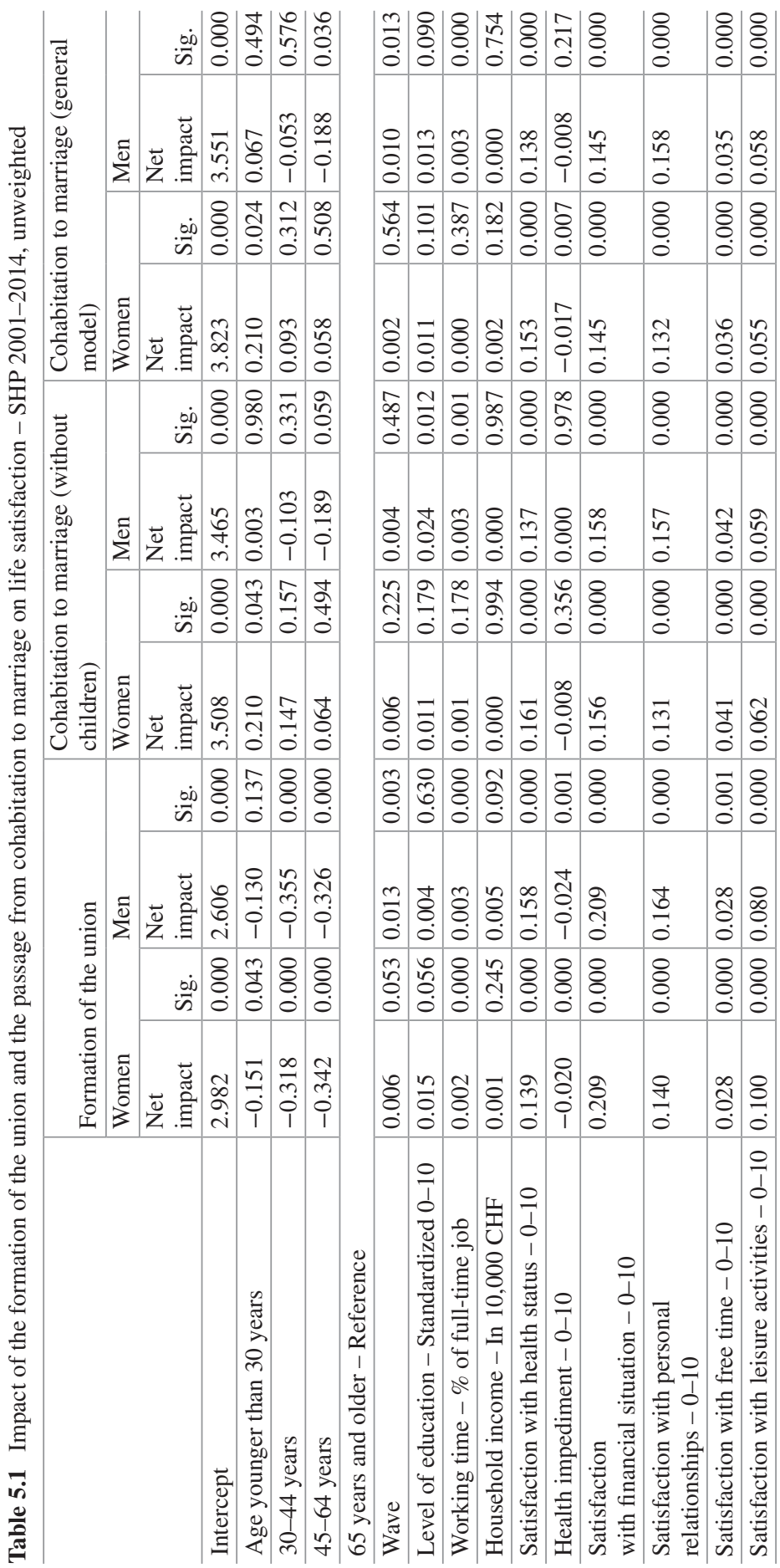




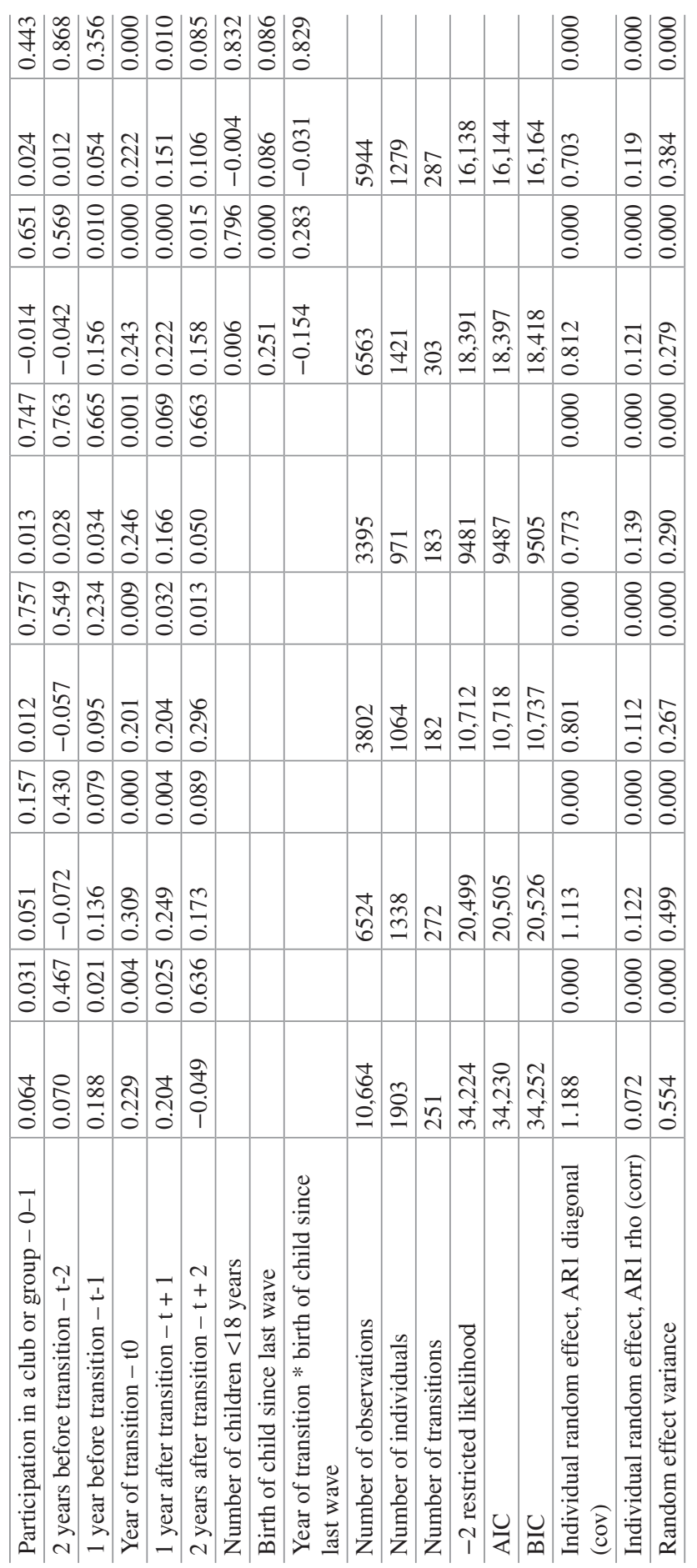


The formation of the union is characterized by the transition from the singleperson household to the couple living together, without any other person (especially children), to control for the influence of other events.

In our sample, 251 women and 272 men experienced this transition during the 14 waves considered. The coefficient indicated that the positive impact of the formation of the union on life satisfaction can be perceived one year before the transition $(\mathrm{t}-1)$, especially for women $(0.19, p=0.021$, compared to $0.14, p=0.079$ for men), and reaches a peak just in the year of the transition (t0) $(0.23$ for women, 0.31 for men). The positive impact generally lasts one more year $(t+1)$ for both women and men $(0.20$ and 0.25$)$ and vanishes two years after the transition (no longer significant for both sexes).

In studying the transition from cohabitation to marriage (182 transitions for women and 183 for men in the simple model, and 303 and 287 in the general model, respectively), we found an increase in life satisfaction from both women and men the in the year of transition ( $\mathrm{t} 0)(0.20$ and 0.24 for women and 0.25 and 0.22 for men, respectively) and one year after $(t+1)(0.20$ and 0.22 , and 0.17 and 0.15 for men, respectively). In the second year after marriage $(t+2)$, its positive impact was still perceivable among women $(0.30$ and 0.16$)$ but was no longer significant among men. Additionally, the positive impact starts before the transition (t-1) in the general model, but only for women (0.16). Even when we control for the number of children in the household and for the birth of a child during the previous 12 months (given that this event is often concomitant with marriage in Switzerland), the results did not change. However, when marriage and the birth of a child happened in the same year, we did not find a supplementary impact on life satisfaction.

The models presented in Table 5.2 were run to predict the impact of the next step in the family construction, the birth of children. Therefore, we distinguished the rank of children and separately analysed the birth of the first, the second and the third (and subsequent) child (or children).

The impact of this transition on life satisfaction follows a different pattern according to the rank of children and the sex of the respondents. We first noted a positive impact at the time of each birth among women, even if this positive impact decreased somewhat with the rank of children ( 0.39 for the 1 st child, 0.23 for the 2 nd child, 0.21 for the $3 \mathrm{rd}$ child and subsequent children). The impact is also positive the year before $(t-1)$ each of those transitions $(0.29,0.14$ and 0.21 , respectively), revealing a positive effect of pregnancy on life satisfaction. Furthermore, this positive influence generally does not last among women; it can only be marginally noted one year after the birth of the third child $(0.20, p=0.036)$. 
Table 5.2 Impact of the birth of children on life satisfaction - SHP 2001-2014, unweighted

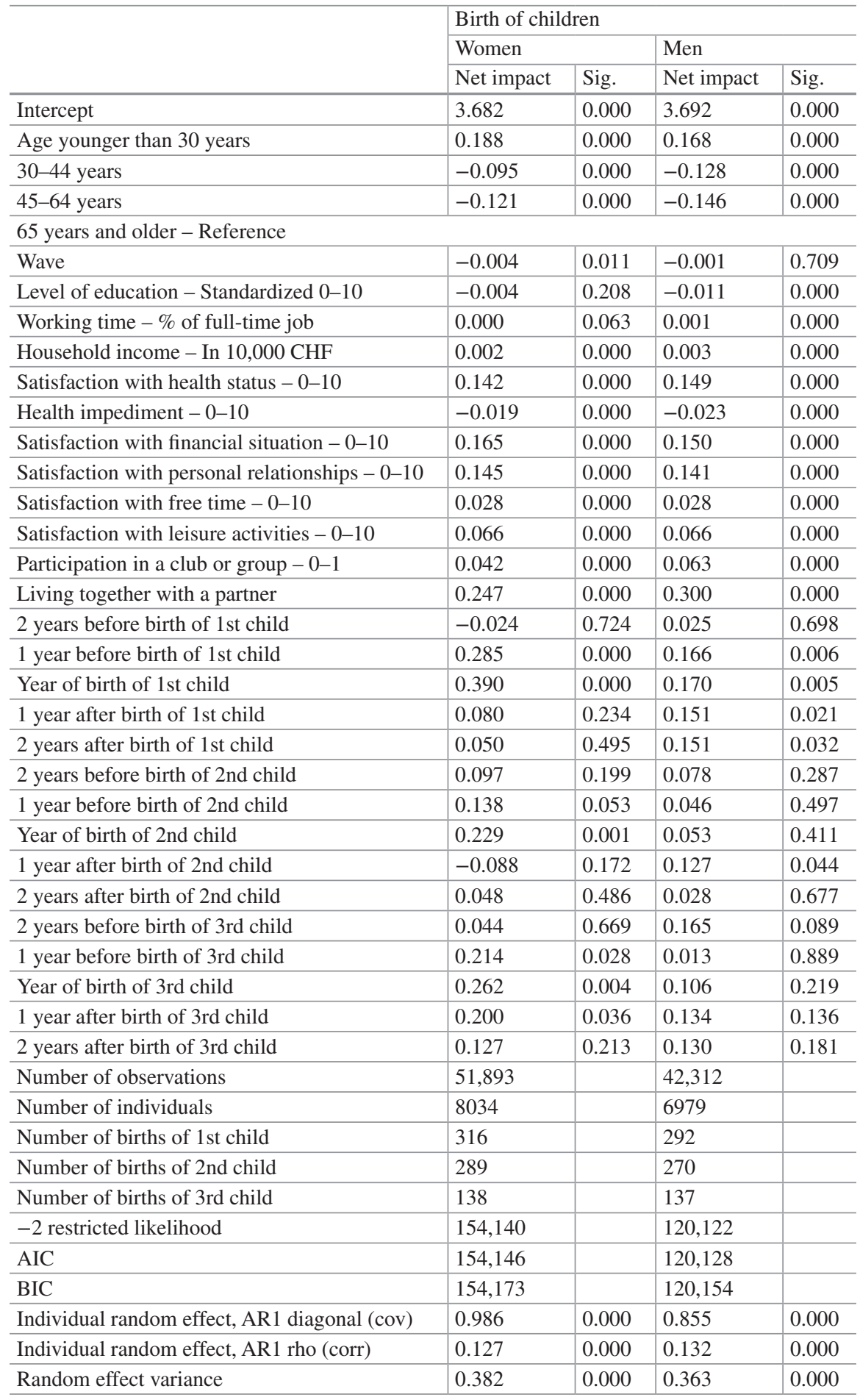


The situation is different for men; only the birth of the first child has a notable impact, but this impact is more constant and persistent on the mid-term $(0.17$ at t- 1 and $\mathrm{t} 0$, and 0.15 at $\mathrm{t}+1$ and $\mathrm{t}+2)$. Apart from a marginal impact one year after the birth of the second child $(0.13, p=0.044)$, other successive births do not convey such a positive feeling of satisfaction.

\section{The Family Dissolution}

Table 5.3 shows the impact of the dissolution of the union, namely living without a partner after having experienced cohabitation during the previous wave. We distinguished two forms of dissolution: the generic separation, irrespective of the reason (break up, divorce, widowhood, etc.), to which we added a specific effect in case of widowhood, to take into account the very different nature of this event.

The impact of separation on life satisfaction shows a similar pattern for women and men, but with a temporal gap. The negative impact is felt earlier and stronger by women $(-0.21,-0.49$ and -0.63 at $\mathrm{t}-2, \mathrm{t}-1$ and $\mathrm{t} 0$, respectively), but it vanishes sooner $(-0.28$ at $t+1$, no longer significant at $t+2)$. On the other hand, men tend to perceive a somewhat smoother impact until the time of the event $(-0.18,-0.36$, -0.61 , at $\mathrm{t}-2, \mathrm{t}-1$ and $\mathrm{t} 0$, respectively), but the influence tends to persist over time $(-0.53$ at $\mathrm{t}+1$ and -0.26 at $\mathrm{t}+2)$.

The total influence of widowhood on life satisfaction is composed of the impact of generic separation cumulated ${ }^{12}$ to the specific effect of widowhood, given that the latter also comprises a separation. The total effect of widowhood is particularly detrimental to life satisfaction for both women and men at the time of the event $(-1.1$ and -0.97 , respectively), as well as the year after $(-0.49$ and -0.53 at $t+1$, respectively). As for generic separation, the effect lasts longer for men and is still perceivable two years after $(-0.26)$, but can be observed sooner among women $(-0.49$ in $\mathrm{t}-1)$.

We also included a specific effect that measured the interaction of the presence of at least a minor child in the household at the time of the separation. Interestingly, its effect is slightly positive for women $(0.16, p=0.081)$ but largely negative for men $(-0.44, p=0.002)$. In case of separation, the presence of a child seems then to represent a resource for women, helping attenuate the negative effect on life satisfaction, but engenders an increased dissatisfaction for men.

The last transition we examined was the departure of children from the family nest while the couple remained together. In general, the impact of this transition was not significant in the short term or in the medium term for both women and men. The only exception included the departure of the last (often the youngest) household's child: in this case, the life satisfaction of fathers slightly increases (Table 5.4).

\footnotetext{
${ }^{12}$ In the calculation, only significant impacts were taken into account.
} 
Table 5.3 Impact of the dissolution of the union on life satisfaction - SHP 2001-2014, unweighted

\begin{tabular}{|c|c|c|c|c|}
\hline & \multicolumn{4}{|c|}{ Dissolution of the union } \\
\hline & \multicolumn{2}{|c|}{ Women } & \multicolumn{2}{|l|}{ Men } \\
\hline & Net impact & Sig. & Net impact & Sig. \\
\hline Intercept & 3.892 & 0.000 & 3.886 & 0.000 \\
\hline Age younger than 30 years & 0.162 & 0.000 & 0.010 & 0.815 \\
\hline $30-44$ years & -0.023 & 0.449 & -0.126 & 0.000 \\
\hline 45-64 years & -0.053 & 0.035 & -0.162 & 0.000 \\
\hline \multicolumn{5}{|l|}{65 years and older - Reference } \\
\hline Wave & -0.009 & 0.000 & -0.002 & 0.163 \\
\hline Level of education - Standardized $0-10$ & 0.009 & 0.019 & 0.008 & 0.055 \\
\hline Working time $-\%$ of full-time job & 0.000 & 0.402 & 0.002 & 0.000 \\
\hline Household income - In 10,000 CHF & 0.003 & 0.000 & 0.002 & 0.022 \\
\hline Satisfaction with health status $-0-10$ & 0.142 & 0.000 & 0.144 & 0.000 \\
\hline Health impediment $-0-10$ & -0.015 & 0.000 & -0.020 & 0.000 \\
\hline Satisfaction with financial situation $-0-10$ & 0.176 & 0.000 & 0.162 & 0.000 \\
\hline Satisfaction with personal relationships $-0-10$ & 0.137 & 0.000 & 0.130 & 0.000 \\
\hline Satisfaction with free time $-0-10$ & 0.034 & 0.000 & 0.036 & 0.000 \\
\hline Satisfaction with leisure activities $-0-10$ & 0.056 & 0.000 & 0.059 & 0.000 \\
\hline Participation in a club or group $-0-1$ & 0.027 & 0.054 & 0.052 & 0.000 \\
\hline Presence of children $<18$ years $-0-1$ & 0.000 & 0.998 & 0.017 & 0.364 \\
\hline 2 years before end of union & -0.210 & 0.001 & -0.183 & 0.004 \\
\hline 1 year before end of union & -0.489 & 0.000 & -0.362 & 0.000 \\
\hline Year of end of union & -0.625 & 0.000 & -0.610 & 0.000 \\
\hline 1 year after end of union & -0.279 & 0.000 & -0.532 & 0.000 \\
\hline 2 years after end of union & -0.054 & 0.392 & -0.258 & 0.000 \\
\hline 2 years before widowhood & 0.158 & 0.153 & 0.437 & 0.016 \\
\hline 1 year before widowhood & -0.093 & 0.364 & 0.354 & 0.042 \\
\hline Year of widowhood & -0.471 & 0.000 & -0.359 & 0.037 \\
\hline 1 year after widowhood & -0.215 & 0.043 & 0.297 & 0.123 \\
\hline 2 years after widowhood & -0.032 & 0.774 & -0.116 & 0.582 \\
\hline Year of end of union $*$ presence of children $<18$ years & 0.158 & 0.081 & -0.438 & 0.002 \\
\hline Number of observations & 35,345 & & 29,770 & \\
\hline Number of individuals & 5155 & & 4587 & \\
\hline Number of ends of union & 620 & & 400 & \\
\hline Number of widowhoods & 144 & & 34 & \\
\hline-2 restricted likelihood & 102,858 & & 82,573 & \\
\hline AIC & 102,864 & & 82,579 & \\
\hline $\mathrm{BIC}$ & 102,890 & & 82,604 & \\
\hline Individual random effect, AR1 diagonal (cov) & 0.933 & 0.000 & 0.791 & 0.000 \\
\hline Individual random effect, AR1 rho (corr) & 0.130 & 0.000 & 0.111 & 0.000 \\
\hline Random effect variance & 0.356 & 0.000 & 0.371 & 0.000 \\
\hline
\end{tabular}


Table 5.4 Impact of the departure of children on life satisfaction - SHP 2001-2014, unweighted

\begin{tabular}{|c|c|c|c|c|}
\hline & \multicolumn{4}{|c|}{ Departure of children } \\
\hline & \multicolumn{2}{|c|}{ Women } & \multicolumn{2}{|l|}{ Men } \\
\hline & Net impact & Sig. & Net impact & Sig. \\
\hline Intercept & 3.934 & 0.000 & 3.948 & 0.000 \\
\hline Age younger than 30 years & 0.349 & 0.000 & 0.138 & 0.141 \\
\hline $30-44$ years & 0.018 & 0.718 & -0.116 & 0.016 \\
\hline $45-64$ years & -0.040 & 0.379 & -0.196 & 0.000 \\
\hline \multicolumn{5}{|l|}{65 years and older - Reference } \\
\hline Wave & -0.006 & 0.005 & 0.005 & 0.035 \\
\hline Level of education - Standardized 0-10 & 0.008 & 0.128 & 0.011 & 0.037 \\
\hline Working time $-\%$ of full-time job & 0.000 & 0.150 & 0.002 & 0.000 \\
\hline Household income - In 10,000 CHF & 0.002 & 0.019 & 0.001 & 0.296 \\
\hline Satisfaction with health status $-0-10$ & 0.135 & 0.000 & 0.142 & 0.000 \\
\hline Health impediment $-0-10$ & -0.018 & 0.000 & -0.026 & 0.000 \\
\hline Satisfaction with financial situation $-0-10$ & 0.167 & 0.000 & 0.155 & 0.000 \\
\hline Satisfaction with personal relationships $-0-10$ & 0.156 & 0.000 & 0.133 & 0.000 \\
\hline Satisfaction with free time $-0-10$ & 0.028 & 0.000 & 0.030 & 0.000 \\
\hline Satisfaction with leisure activities $-0-10$ & 0.048 & 0.000 & 0.050 & 0.000 \\
\hline Participation in a club or group $-0-1$ & 0.027 & 0.143 & 0.074 & 0.000 \\
\hline Number of children $<18$ years & -0.007 & 0.571 & -0.015 & 0.223 \\
\hline 2 years before departure & 0.009 & 0.791 & 0.070 & 0.042 \\
\hline 1 year before departure & 0.012 & 0.697 & 0.015 & 0.639 \\
\hline Year of departure & 0.009 & 0.824 & -0.069 & 0.079 \\
\hline 1 year after departure & -0.024 & 0.454 & 0.004 & 0.900 \\
\hline 2 years after departure & -0.033 & 0.353 & -0.022 & 0.555 \\
\hline Departure of last child & 0.037 & 0.510 & 0.163 & 0.005 \\
\hline Number of observations & 19,470 & & 16,532 & \\
\hline Number of individuals & 2875 & & 2528 & \\
\hline Number of departure of children & 1133 & & 919 & \\
\hline Number of departure of last child & 485 & & 371 & \\
\hline-2 restricted likelihood & 54,772 & & 44,200 & \\
\hline AIC & 54,778 & & 44,206 & \\
\hline BIC & 54,802 & & 44,229 & \\
\hline Individual random effect, AR1 diagonal (cov) & 0.827 & 0.000 & 0.711 & 0.000 \\
\hline Individual random effect, AR1 rho (corr) & 0.114 & 0.000 & 0.117 & 0.000 \\
\hline Random effect variance & 0.367 & 0.000 & 0.351 & 0.000 \\
\hline
\end{tabular}

\section{Conclusion and Discussion}

In this study, we evaluated the relationship between life satisfaction and five family transitions, using a longitudinal approach. Specifically, we studied mid-term individual trajectories, with the aim to understand not only the impact of several events 
on well-being, but to capture their duration. Focusing on the Swiss context, we used MLMs for their power in studying changes.

Our main findings can be summarised as follows. First, the creation of a couple increases men's and women's well-being, but the positive effect tends to vanish after a couple of years. Our first hypothesis is therefore confirmed and enables us to extend the previous findings on the "honeymoon effect" in the Swiss context. An increase in life satisfaction also appears for the second event (transition from cohabitation to marriage), and it is clearly stronger for women than for men. The birth of children is associated with increased happiness, but this association is differentiated over time and, again, between females and men. Women declare being happier until the time of the birth, whilst men show an effect the year after the birth and only for the first child.

It is not surprising that the break in a relationship causes unhappiness for the individuals involved but, in this case, women and men react differently. Women seem to suffer more at the moment of the disruption and the years before this event. However, they seem to improve their well-being quickly after the event. On the other hand, men show their unhappiness only at the time of the break, but continue to suffer during the subsequent years. Our results also show that the departure of a child does not induce a significant change in the level of satisfaction, as previous literature has underlined. However, when the effect appeared (as in case of men), it was positive. We therefore interpreted it as if Swiss parents were prepared for this event and tended to have an alternative role in which they continued to build their identity.

To the best of our knowledge, our study can be considered the first that takes into consideration both the association of the mentioned five family events with life satisfaction and their duration over time in the Swiss context. We underlined how family events have a crucial impact on the happiness of individuals and how strong the differences between genders are. In focusing on the Swiss context, it is not hazardous to think that at least part of the divergences between men and women are connected with the conservative gender culture, which determines that men invest rather in the labour market and that still associates women with the main roles of wife and mother. The next step would be to confirm these findings in different cultural contexts, as data from the CNEF project could allow.

\section{References}

Aassve, A., Goisis, A., \& Sironi, M. (2012). Happiness and childbearing across Europe. Social Indicators Research, 108(1), 65-86.

Amato, P. R., \& Booth, A. (1991). Consequences of parental divorce and marital unhappiness for adult well-being. Social Forces, 69(3), 895-914.

Angeles, L. (2010). Adaptation and anticipation effects to life events in the United Kingdom (Department of Economics Discussion Paper 08). University of Glasgow. http://repo.sire.ac.uk/ bitstream/handle/10943/134/SIRE_DP_2010_01.pdf?sequence=1\&isAllowed=y. Accessed 25 June 2016. 
Anusic, I., Stevie, C. Y., \& Lucas, R. E. (2013). Testing set-point theory in a Swiss National Sample: Reaction and adaptation to major life events. Social Indicators Research, 119, 1265-1288.

Beaupré, P., Turcotte, P., \& Milan, A. (2006). When is junior moving out? Transitions from the parental home to independence. Canadian Social Trends, 82, 9-15.

Billari, F. C. (2009). The happiness commonality: Fertility decisions in low-fertility settings. Keynote address at conference on How generations and gender shape demographic change: Toward policies based on better knowledge, UNECE, Geneva, Switzerland. Retrieved from www.unece.org/fileadmin/DAM/pau/_docs/ggp/2008/GGP_2008_GGConf_Publ_1_ Chapter-1.pdf

Blanchflower, D. G., \& Oswald, A. J. (2004). Money, sex and happiness: An empirical study. Scandinavian Journal of Economics, 106(3), 393-415.

Bouchard, G. (2014). How do parents react when their children leave home? An integrative review. Journal of Adult Development, 21(2), 69-79.

Clark, A. E., Diener, E., Georgellis, Y., \& Lucas, R. E. (2008). Lags and leads in life satisfaction: A test of the baseline hypothesis. The Economic Journal, 118(529), F222-F243.

Dare, J. S. (2011). Transitions in midlife women's lives: Contemporary experiences. Health Care for Women International, 32, 111-133.

Della Giusta, M., Jewell, S. L., \& Kambhampati, U. S. (2011). Gender and life satisfaction in the UK. Feminist Economics, 17(3), 1-34.

Dolan, P., Peasgood, T., \& White, M. (2008). Do we really know what makes us happy? A review of the economic literature on the factors associated with subjective well-being. Journal of Economic Psychology, 29(1), 94-122.

Erickson, J. J., Martinengo, G., \& Hill, E. J. (2010). Putting work and family experiences in context: Differences by family life stage. Human Relations, 63, 955-979.

Harkins, E. B. (1978). Effects of empty nest transition on self-report of psychological and physical well-being. Journal of Marriage and the Family, 40, 549-556.

Hox, J. J. (2002). Multilevel analysis. Techniques and applications. Mahwah: Lawrence Erlbaum Associates.

Johnson, D. R., \& Wu, J. (2002). An empirical test of crisis, social selection, and role explanations of the relationship between marital disruption and psychological distress: A pooled time-series analysis of four-wave panel data. Journal of Marriage and Family, 64(1), 211-224.

Kalmijn, M. (2009). Country differences in the effects of divorce on well-being: The role of norms, support, and selectivity. European Sociological Review, 32(5), 475-490.

Kalmijn, M., \& Moden, C. W. S. (2009). Are the negative effects of divorce on well-being dependent on marital quality? Journal of Marriage and Family, 68(5), 1197-1213.

Kohler, H. P., Behrman, J. R., \& Skytthe, J. R. (2005). Partner children = happiness? The effects of partnerships and fertility on well-being. Population and Development Review, 31(3), 407-445.

Lavee, Y., Sharlin, S., \& Katy, R. (1996). The effect of parenting stress on marital quality an integrated mother-father model. Journal of Family Issues, 17(1), 114-135.

Lipps, O. (2010). Income imputation in the Swiss Household Panel 1999-2007 (FORS Working Paper Series, 1).

Lucas, R. (2005). Time does not heal all wounds. A longitudinal study of reaction and adaptation to divorce. Psychological Science, 16(12), 945-950.

Lucas, R., \& Clark, A. E. (2006). Do people really adapt to marriage? Journal of Happiness Studies, 7, 405-426.

Lucas, R., Clark, A. E., Georgellis, Y., \& Diener, E. (2003). Reexamining adaptation and the set point model of happiness: Reactions to changes in marital status. Journal of Personality and Social Psychology, 84(3), 527-539.

Myrskylä, M., \& Margolis, R. (2014). Happiness: Before and after kids. Demography, 51(5), $1843-1866$.

Raup, J. L., \& Myers, J. E. (1989). The empty nest syndrome: Myth or reality? Journal of Counseling and Development, 68, 180-183.

Simon, R. W. (1992). Parental role strains, salience of parental identity and gender differences in psychological distress. Journal of Health and Social Behavior, 33(1), 25-35. 
Singer, J. D., \& Willett, J. B. (2003). Applied longitudinal data analysis: Modeling change and event occurrence. Oxford: University Press.

Stutzer, A., \& Frey, B. (2006). Does marriage make people happy or do happy people get married? The Journal of Socio-Economics, 35, 326-347.

Tillmann, R., Voorpostel, M., Antal, E., Kuhn, U., Lebert, F., Ryser, V.-A., Lipps, O., \& Wernli, B. (2016). The Swiss household panel study: Observing social change since 1999. Longitudinal and Life Course Studies, 7(1), 64-78.

Umberson, D., Pudrovska, T., \& Reczek, C. (2010). Parenthood, childlessness, and well-being: A life course perspective. Journal of Marriage and Family, 72, 612-629.

Vignoli, D., Pirani, E., \& Salvini, S. (2014). Family constellations and life satisfaction in Europe. Social Indicators Research, 117(3), 967-986.

White, L., \& Edwards, J. N. (1990). Emptying the nest and parental well-being: An analysis of national panel data. American Sociological Review, 55, 235-242.

Williams, K., \& Umberson, D. (2004). Marital status, marital transitions, and health: A gendered life course perspective. Journal of Health and Social Behavior, 45(1), 81-98.

Zimmermann, A., \& Easterlin, R. (2006). Happily ever after? Cohabitation, marriage, divorce, and happiness in Germany. Population and Development Review, 32(3), 511-528.

Open Access This chapter is licensed under the terms of the Creative Commons Attribution 4.0 International License (http://creativecommons.org/licenses/by/4.0/), which permits use, sharing, adaptation, distribution and reproduction in any medium or format, as long as you give appropriate credit to the original author(s) and the source, provide a link to the Creative Commons license and indicate if changes were made.

The images or other third party material in this chapter are included in the chapter's Creative Commons license, unless indicated otherwise in a credit line to the material. If material is not included in the chapter's Creative Commons license and your intended use is not permitted by statutory regulation or exceeds the permitted use, you will need to obtain permission directly from the copyright holder.

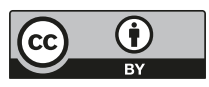

